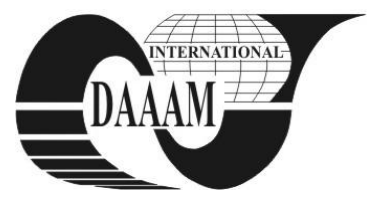

\title{
INFLUENCE OF HYDROCOLLOIDS ON THE RHEOLOGICAL BEHAVIOR OF BLUEBERRIES YOGURT
}

\author{
OROIAN, M[ircea] A[drian]; GUTT, S[onia] \& GUTT, G[heorghe]
}

\begin{abstract}
The purpose of this work is to observe the influence of three hydrocolloids on the rheological behaviour of the blueberries set yogurt. For this study where used three hydrocolloids in different concentration $(0,0.2,0.4$ and $0.8 \%$ respectively) and starter culture (Lactobacillus bulgaricus and Streptococcus thermophilus). The rheological properties of the blueberries yogurt obtained from the milk were investigated with a viscometer at different shear rates, using $R V$ spindles. All the three hydrocolloids increased the viscosity of the samples. The sample with the highest concentration of $\kappa$ carrageenan presented the highest viscosity, shear stress and consistency, while the samples without hydrocolloids presented the smallest viscosity. The concentration of hydrocolloid has not a big influence on the flow index amount.

Key words: $\kappa$-carrageenan, agar-agar, starch, yogurt
\end{abstract}

\section{INTRODUCTION}

Nowdays, the hydrocolloids are worldwide spread in many applications of food industry. The most important aspect of hydrocolloids in food application is the manner they change the rheological behavior (Muller, 1973). The uses of hydrocolloids improve the rheological behavior of food products, making them more firme, and with an increased consistency.

The hydrocolloids were used in the last decades in the ketchup sauces, syrups, ice cream, instant foods, beverages, fruit yogurt and confectionaries, marshmallows and candies (Aliste et.al. 2000, Dogan et.al.2004, Kayacier et.al.2006).

The hydrocolloids are used in the yogurt production because they increase the viscosity and prevent the separation of the whey. The hydrocolloids were used to stabilize the texture (Koksoy et.al.2004), as fat replacers.

The purpose of this work is to observe the rheological differences generated by the three hydrocolloids on the rheological behavior of the blueberries yogurt. The next researches will be on the sensorial evaluation of the influence of hydrocolloids on the blueberries yogurt samples.

\section{EXPERIMENTAL}

Milk with a TSS (total soluble content) 12,5\% reconstitute, Lactobacillus bulgaricus and Streptococcus thermophilus pure starter culture DI PROX 973 provided by Enzymes \& Derivates, agar-gar provided by Scharlau, Spain, $\kappa$-carragenan and starch; orbital shaker; thermostat; Brookfield viscometer Model RV- DV II Pro, with disk spindle.

All the samples were made using reconstituted milk. The starter culture is extracted from the freezer and thawed. The milk was heated at $90{ }^{\circ} \mathrm{C}$ for $5 \mathrm{~min}$, after it, the samples are cold to $70^{\circ} \mathrm{C}, 60^{\circ} \mathrm{C}$ and $50^{\circ} \mathrm{C}$ for starch, $\kappa$-carragenan and agaragar respectively. The starter culture was inoculated at $43{ }^{\circ} \mathrm{C}$. For a good activation of the starter culture, the samples are shook for $15 \mathrm{~min}$ on an orbital shaker at $150 \mathrm{rpm}$. The starter culture was inoculated at $43{ }^{0} \mathrm{C}$. All the samples were maintained at $43{ }^{\circ} \mathrm{C}$ for $5 \mathrm{~h}$ in the thermostat.

The samples in $300 \mathrm{ml}$ of beaker with $8.56 \mathrm{~cm}$ diameter (according to the Brookfield requests) were kept in a thermostatically controlled water bath for about $10 \mathrm{~min}$ before measurements in order to attain desirable temperature of $25^{\circ} \mathrm{C}$.

The shear rate versus shear stress data were interpreted using the power law expression

$$
\tau=\mathrm{k} \cdot \dot{\gamma}^{\mathrm{n}}
$$

Where: $\tau$ - shear stress $\left(\mathrm{N} / \mathrm{m}^{2}\right), \gamma$ is the shear rate $\left(\mathrm{s}^{-1}\right), \mathrm{n}$ is the flow behaviour index, $k$ is the consistency index $\left(\mathrm{Ns}^{\mathrm{n}} / \mathrm{m}^{2}\right)$.

The values for the flow behaviour index $n$, were obtained from plots of log shear stress versus log rotational speed; the slope of the line (if the dependence is sufficiently close to a linear one) is simply equal to the flow index of the fluid, $n$.

The shear stress is calculated using the next equation:

$$
\tau_{\mathrm{i}}=\mathrm{k}_{\tau} \cdot \alpha_{\mathrm{i}} \cdot \mathrm{C}
$$

Where: $\tau_{\mathrm{i}}$ - shear stress $\left[\right.$ dyne $\left./ \mathrm{cm}^{2}\right], \mathrm{k}_{\tau}=0.119$, this constant is for the spindle nos $2, \alpha_{i}-$ torque dial, $\%, \mathrm{C}-7,187 \mathrm{dyne} / \mathrm{cm}$ for RV viscometer

The shear rate is calculated using the next equation:

$$
\dot{\gamma}_{\mathrm{i}}=\mathrm{k}_{\gamma}(\mathrm{n}) \cdot \mathrm{N}_{\mathrm{i}}
$$

Where: $\dot{\gamma}_{\mathrm{i}}-$ shear rate, $\mathrm{s}^{-1}, \mathrm{k}_{\gamma}(\mathrm{n})-$ constant, depends by the value of $n, N_{i}-$ rotational speed, rpm

\section{RESULTS AND DISCUSION}

Viscosity data showed that all blueberries yogurt samples under examination were non-Newtonian fluids, since the values for the flow behaviour index, $n$ were under 1 , which was an indicative of the thixotropy nature of culture yogurt. The power law equation was found to be an adequate model to describe the flow behaviour of the samples in this study. The $\mathrm{R}^{2}$ values of the equations $\log$ shear rate versus log rotational speed were found to vary from 0.98 to 0.998 . The flow index behaviour $(n)$ of the power law model ranged between 0.28 and 0.329 . Although $n$ does not have a strong dependence on the concentration of hydrocolloids. The Brookfield viscometer with disk spindles (Mitschka, 1982) represents a good method to determine non-Newtonian fluid properties.

The addition of hydrocolloids and the increase in the amount of them in the blueberries yogurt samples increased the shear thinning properties of the yogurt samples (tab1, fig.1, fig.2). These results further indicated that addition of $\kappa$ carrageenan caused greater shear thinning properties of yogurt samples, whereas starch and agar-agar showed a smallest effect than $\kappa$-carrageenan on the shear thinning behaviour of the yogurt samples.

The $\kappa$-carrageenan has the highest index of consistency and apparent viscosity due to their capacity to associate with milk products and proteins (Perez-Mateos, 2001), and their highwater binding capacity, this is likely because of the hydrophilic sugar structure as well as the amorphous molecular arrangement of the polysaccharide chains (Suzuki \& Nakagami, 1999). 


\begin{tabular}{|c|l|c|c|}
\hline $\begin{array}{c}\text { Exp. } \\
\text { No. }\end{array}$ & \multicolumn{1}{|c|}{ Sample } & $\begin{array}{c}\text { Apparent } \\
\text { viscosity } \\
{[\mathrm{Pa} \cdot \mathrm{s}]^{*}}\end{array}$ & $\begin{array}{c}\text { Flow index } \\
{[n]}\end{array}$ \\
\hline 1. & Blanck & 22.12 & 0.280 \\
\hline 2. & Starch $0.2 \%$ & 29.08 & 0.302 \\
\hline 3. & Starch $0.4 \%$ & 33.34 & 0.310 \\
\hline 4. & Starch $0.8 \%$ & 39.28 & 0.323 \\
\hline 5. & Agar-agar $0.2 \%$ & 30.4 & 0.297 \\
\hline 6. & Agar-agar $0.4 \%$ & 33.64 & 0.305 \\
\hline 7. & Agar-agar $0.8 \%$ & 40.28 & 0.317 \\
\hline 8. & Carrageenan $0.2 \%$ & 35.02 & 0.305 \\
\hline 9. & Carrageenan $0.4 \%$ & 42.95 & 0.314 \\
\hline 10. & Carrageenan $0.8 \%$ & 54.88 & 0.329 \\
\hline
\end{tabular}

Tab. 1. Changes in the rheological properties of the yogurt samples influenced by the three hydrocolloids added

* The apparent viscosity was measured at $2.5 \mathrm{rpm}$

The starch improved the rheological properties of the blueberries yogurt samples, due to the water-bind capacity, high molecular weight and due to the forming of the casein-starch system, the water-bind capacity. The ability of starches to thicken, gel and hold water has been exploited in yogurt manufacture, also some workers have found that casein interacts with some types of starch increasing viscosity but promoting phase separation (Antonov, 1999), but not in the samples with low levels of amylopectin added.

The influence of the agar-agar on the rheological behavior of the blueberries yogurt is quite the same with the starch samples; the agar-agar has a great water-binding capacity. Gelation of agar involves conversion from a fluctuating disordered coil conformation in solution to a rigid ordered structure (co-axial double helix) which forms the junction zones of the gel network, thus giving the peculiar viscoelastic character to the solid emulsion-continuous phase (Piazza \& Benedetii, 2010).

Agar-agar gelation follows a "crosslinked network" model. In this model, a gradual change from a homogeneous aqueous sol to an elastic and turbid gel network occurs during cooling and characteristic gelation parameters, in particular the setting temperature and the gelling time, are attended to depend on agar concentration (Labropoulos, 2002).

The temperature of hydrocolloid insertion has a great impact on the syneresis of yogurt samples. Each hydrocolloid used has a different temperature of adding to the yogurt sample, for example aga-agar was added at $43^{\circ} \mathrm{C}, \kappa$-carrageenan $60^{\circ} \mathrm{C}$, while the starch was added at $70^{\circ} \mathrm{C}$. If the hydrocolloid is inserted at a temperature higher than the gel formation temperature (proper for each hydrocolloid), it generate the syneresis of the sample.

\section{CONCLUSION}

The present study showed that all the three hydrocolloids tested (agar-agar, $\kappa$-carrageenan, and starch) can be used to improve the rheological properties of the blueberries yogurts (viscosity, consistency, flow index).
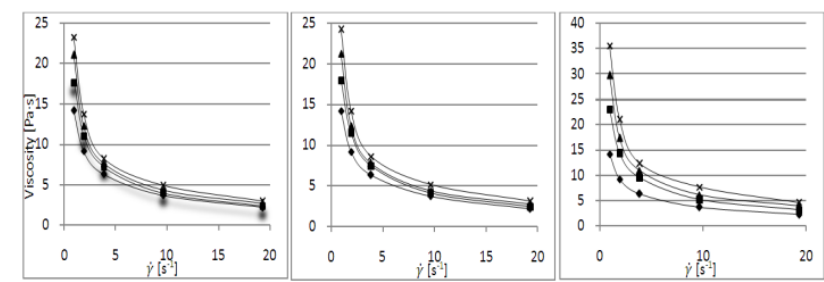

Fig. 1. Changes in the viscosity in the blueberries yogurt: a. samples with starch, b. samples with agar-agar, c. samples with $\kappa$-carrageenan blanck sample, $\longrightarrow 0.2 \%$ hydrocolloid, $\longrightarrow 0.4 \%$ hydrocolloid, $\longrightarrow 0.8 \%$ hydrocolloid

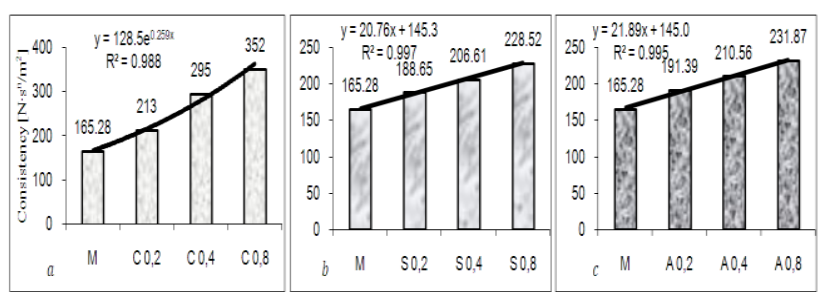

Fig. 2. Changes in the consistency in the blueberries yogurt: a. samples with $\kappa$-carrageenan, b. samples with starch, c. samples with agar-agar

The apparent viscosity and the consistency index increased with the addition of the hydrocolloids and the increase in their concentration. The samples with starch had the texture of a yogurt for all the concentration, while the samples with agaragar and carrageenan from the $0.4 \%$ addition of hydrocolloid the texture was like a gel, not proper for a yogurt sample. Starch is the suitable hydrocolloid for improving the rheological behaviour of yogurt. The temperature of hydrocolloid insertion has a great impact on the syneresis of yogurt samples. If the hydrocolloid is inserted at a temperature higher than the gel formation temperature (proper for each hydrocolloid), it generate the syneresis of the sample.

\section{ACKNOLEDGEMENT}

This paper was supported by the project "Knowledge provocation and development through doctoral research PRODOCT - Contract no. POSDRU/88/1.5/S/52946 ", project cofunded from European Social Fund through Sectoral Operational Program Human Resources 2007-2013.

\section{REFERENCES}

Aliste, A. J., Vieira, F. F., \& Del Mastro, N. L. (2000) Radiation effects on agar, alginates and carrageenan to be used as food additives. Radiation Physics and Chemistry, 57(2), 305-308, ISSN: 0969-806X

Antonov, Y. A., Lefebvre, J., \& Doublier, J. L. (1999) On the one-phase state of aqueous protein uncharged polymer systems: Casein-guar gum system. Journal of Applied Polymer Science, 71(3), 471-482. ISSN: 1097-4628

Aysel Koksoy, Meral Kilic (2004) Use of hydrocolloids in textural stabilization of a yoghurt drink, ayran. Food Hydrocolloids 18 (4), 593-600, ISSN: 0268-005X

Dogan, M., \& Kayacier, A. (2004) Rheological properties of reconstituted hot salep beverage. International Journal of Food Properties, 7(3), 683-691, ISSN: 1532-2386

Labropoulos K.C., Niesz D.E., Danforth S.C.\& Kevrekidis P.G.(2002), Dynamic rheology of agar gels: Theory and experiments, Carbohydrate Polymers 50, 407-415, ISSN: 0144-8617

Kayacier, A., \& Dogan (2006), M. Rheological properties of some gums-salep mixed solutions. Journal of Food Engineering, 72(3), 261-265. ISSN: 0260-8774

Mitschka, P. (1982) A simple conversion of Brookfield R.V.T. readings into viscosity functions, Rheologica Acta, 21, 207-209, ISSN: 1435-1528

Perez-Mateos M, Hurtado JL, Monterno P \& Fernandez-Martin F. (2001) Interactions of kappa-carrageenan plus other hydrocolloids in fish mycosystem gels. Journal of Food Science.; 66:838-843. ISSN 0022-1147

Piazza, L., Benedetii, S. (2010), Investigation on the rheological properties of agar gels, and their role on aroma release in agar limonene solid emulsions, Food Research International, 43, 269-276, ISSN: 0963-9969

Suzuki T, Nakagami H (1999). Effect of crystallinity of microcrystalline cellulose on the compactabitiy and dissolution of tablets. European Journal Pharmacology Biopharmacology 47:225-230. ISSN: 0014-2999 